\title{
Toric intraocular lens implantation in cataract patients with corneal opacity
}

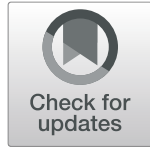

Ho Ra ${ }^{1,2}$, Ho Sik Hwang ${ }^{1}$, Hyun Seung Kim¹, Man Soo Kim and Eun Chul Kim ${ }^{1,2^{*}}$ (D)

\begin{abstract}
Background: To evaluate the effect of toric intraocular lens implantation in cataract patient with corneal opacity and high astigmatism.

Methods: Thirty-one eyes of 31 patients who underwent cataract surgery with toric intraocular lens implantation were included. All patients had corneal opacity with astigmatism. Preoperative total corneal astigmatism was determined considering posterior astigmatism using a rotating Scheimpflug camera (Pentacam ${ }^{\oplus:}$ Oculus, Wetzlar, Germany). At 2 months after toric intraocular lens implantation, we evaluated residual astigmatism, uncorrected visual acuity (UCVA) and best corrected visual acuity (BCVA).

Results: Postoperative UCVA and BCVA $(0.30 \pm 0.17,0.22 \pm 0.16 \mathrm{LogMAR})$ were statistically improved compared to preoperative UCVA and BCVA $(1.2 \pm 0.34,1.1 \pm 0.30$ LogMAR, respectively) $(P<0.01)$. Postoperative residual refractive astigmatism (1.2 $\pm 0.35 \mathrm{D})$ was statistically reduced compared to preoperative refractive astigmatism $(2.4 \pm 0.65 \mathrm{D})$ $(P<0.05)$. Preoperative and postoperative total corneal astigmatism values were not statistically different. All eyes achieved postoperative visual acuity as good as or better than preoperative one. The size of corneal opacity covering pupil had significant negative correlation with postoperative UCVA and BCVA (logMAR) $R=0.91 P<0.05$ and $R=0.92 P<0.05$, respectively).

Conclusion: Toric intraocular lens implantation can improve UCVA, BCVA, and refractive astigmatism in cataract patient with corneal opacity. The size of corneal opacity covering pupil is the major prognostic factor for postoperative visual improvement. Therefore, toric intraocular lens implantation should be considered for cataract patients who have corneal opacity with high astigmatism.
\end{abstract}

Keywords: Corneal opacity, Pupillary area, Cataract, Astigmatism, Toric intraocular lens (TIOL)

\section{Background}

Corneal opacity and cataract are the primary causes of decreased visual acuity. There are two currently surgical treatments options for patients with corneal opacity and cataract. The Triple procedure, simultaneous penetrating keratoplasty (PK), cataract extraction and intraocular lens (IOL) implantation provides a shorter visual rehabilitation period [1]. However, the disadvantages

\footnotetext{
* Correspondence: eunchol@hanmail.net

'Department of Ophthalmology, College of Medicine, Catholic University of Korea, Seoul, South Korea

${ }^{2}$ Department of Ophthalmology, Bucheon St. Mary's Hospital, 327 Sosa-ro, Wonmi-gu, Bucheon, Gyeonggi-do 14647, South Korea
}

include risk of expulsive hemorrhage, inadequate cortical cleaning and inaccuracy in IOL power calculation can decrease postoperative visual acuity [2]. Cataract surgery without PK is sometimes associated with good visual acuity when the corneal opacity partially obscures the pupillary area [3]. Even though visual outcomes after cataract surgery in eyes with corneal opacities can vary, corneal opacity severity may be one of the major prognostic factors of visual acuity [4]. When there is opacity in the patient's cornea, astigmatism usually occurs in the vertical axis (with-the-rule astigmatism), horizontal axis (against-the-rule astigmatism), oblique axis, or irregular axis. When the patient's cornea has regular astigmatism,

(c) The Author(s). 2020 Open Access This article is licensed under a Creative Commons Attribution 4.0 International License, which permits use, sharing, adaptation, distribution and reproduction in any medium or format, as long as you give appropriate credit to the original author(s) and the source, provide a link to the Creative Commons licence, and indicate if changes were made. The images or other third party material in this article are included in the article's Creative Commons licence, unless indicated otherwise in a credit line to the material. If material is not included in the article's Creative Commons licence and your intended use is not permitted by statutory regulation or exceeds the permitted use, you will need to obtain permission directly from the copyright holder. To view a copy of this licence, visit http://creativecommons.org/licenses/by/4.0/. The Creative Commons Public Domain Dedication waiver (http://creativecommons.org/publicdomain/zero/1.0/) applies to the data made available in this article, unless otherwise stated in a credit line to the data. 
good visual acuity can be achieved through astigmatic correction. During cataract surgery, astigmatism can be corrected by prescription glasses, contact lenses, corneal relaxing incisions, astigmatic keratotomy, limbal relaxing incisions, excimer laser ablation, or toric IOL implantation [5]. Toric IOL implantation is the most reliable and effective method for correcting regular astigmatism during cataract surgery. We hypothesized that toric IOL implantation can improve visual acuity in patients with corneal opacity and regular corneal astigmatism.

To the best of our knowledge, there are currently no studies that have evaluated the efficacy of toric IOL implantation in cataract patients with corneal opacity.

\section{Methods}

This study was conducted by performing a retrospective chart review and data analysis. This study was conducted in compliance with Institutional Review Board regulations.

\section{Patients}

Thirty-one patients that had cataract and corneal opacity with regular astigmatism were enrolled from Bucheon St. Mary's Hospital from June 2017 to April 2018.

Inclusion criteria were corneal opacification that involved the visual axis and advanced cataract in patients with corneal astigmatism over 1.5 Diopter and eyes with partially visible anterior capsules and pupillary margins. Patients with a history of any ocular injury or disorder, infection, inflammation, surgery within the prior 6 months and an eye with irregular astigmatism such as keratoconus and keratoectasia were excluded.

\section{Preoperative evaluation}

All patients underwent a complete preoperative ophthalmological examination. The demographic and perioperative data were recorded. Uncorrected and corrected distance visual acuity were expressed as $\log$ MAR. Manifest refraction, biometry and keratometry with the IOLMaster partial coherence interferometry device (Carl Zeiss Meditec AG), corneal topography to exclude irregular astigmatism, slit lamp examination, and dilated funduscopy were performed. The total corneal astigmatism was measured using the Scheimpflug system (Pentacam ${ }^{\circ}$ Oculus, Germany). The preoperative astigmatism was examined repeatedly three times using multiple devices. The IOL manufacturer's web-based toric calculator was used to determine the required cylinder power and axis for implantation. We undercorrected the diopters of toric IOLs rather than overcorrection based on preoperative total corneal astigmatism. The size of corneal opacity covering pupillary area was measured as (vertical + horizontal opacity covering pupil/2) with undilated pupil using image $J$
(National Institutes of Health, Maryland) (Fig. 1). The spherical power of the IOL was chosen on the basis of keratometric values and axial length measurement using the IOLMaster and the SRK/T (Sanders-Retzlaff-Kraff/ Theoretical) formula. The astigmatic power of toric IOL was calculated with the online TECNIS calculators, and surgically induced astigmatism was designated as $0.5 \mathrm{D}$. The corneal steep axis and astigmatism amount were determined using keratometry with the IOLMaster and 3 $\mathrm{mm}$ of the total corneal astigmatism map in the Scheimpflug system. Therefore, lenticular astigmatism of patient was not included as an amount of astigmatism correction using toric IOL.

\section{Operative procedures}

Before surgery, the corneal limbus was marked at the $0^{\circ}, 90^{\circ}$, and $180^{\circ}$ meridians with the patient in a sitting position after instilling topical anesthetic eye drops. All operations were performed under topical anesthesia by a single skilled surgeon (E.C.K) using the Intrepid Infiniti system (Alcon Laboratories, Inc., Fort Worth, TX, USA). The corneal steep axis and $6.0 \mathrm{~mm}$ ring were marked with gentian violet. Surgery was performed through a clear corneal incision at the steep astigmatic axis. After topical ocular anesthesia was applied, a $2.75 \mathrm{~mm}$ clear corneal incision was made using a $2.75 \mathrm{~mm}$ double-blade keratome (Alcon). Sodium hyaluronate 1.0\% (Hyal Plus, LG Life Science, Seoul, Korea) was used to reform and stabilize the anterior chamber. A continuous curvilinear capsulotomy was made with a $6.0 \mathrm{~mm}$ corneal marker using Inamura capsulorhexis forceps (Duckworth \& Kent Ltd., Baldock, UK). Hydrodissection

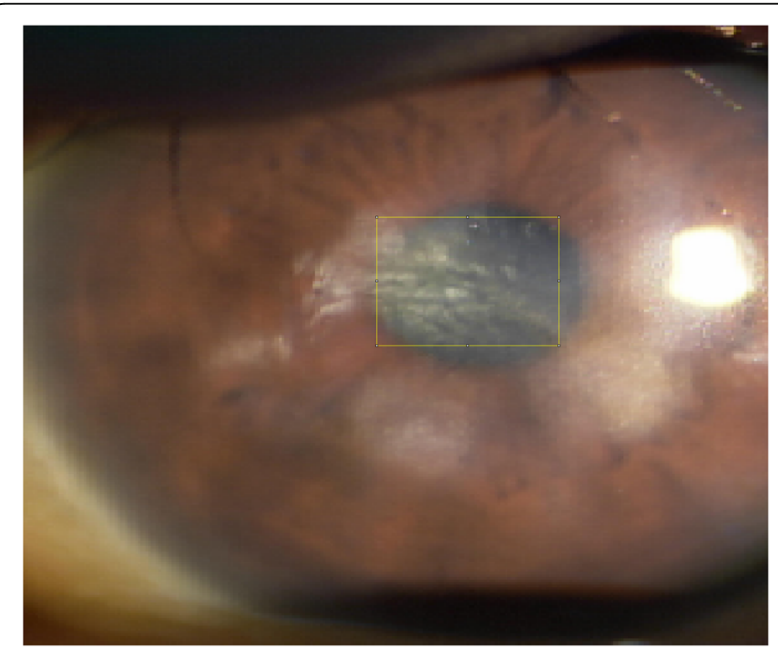

Fig. 1 How to measure the size of corneal opacity covering pupil using image J. The vertical opacity was $2.9 \mathrm{~mm}$ and horizontal opacity was $3.6 \mathrm{~mm}$, so the size of corneal opacity covering pupil is $(2.9+3.6) / 2=3.25 \mathrm{~mm}$ 
and hydrodelineation were achieved using a balanced salt solution. Phacoemulsification was performed using 2.75-mm-sized phaco-tips and infusion/aspiration (I/A) cannulas in the micro- and small-incision groups, respectively. A clear preloaded IOL (Tecnis ZCT; Abbott Medical Optics) was implanted in the capsular bag. Toric markings of IOLs are located under marking of corneal steep axis using retroillumination of operative microscope. The wound was not sutured (Video). Postoperative treatment consisted of gatifloxacin 0.3\% (Gatiflo, Handok, Chungbuk, Korea) and fluorometholone acetate $0.01 \%$ (Ocumetholone, Samil, Seoul, Korea) eye drops four times a day for 4 weeks.

\section{Postoperative evaluation}

After 2 months later, uncorrected and corrected distance visual acuity, manifest refraction, and residual refractive astigmatism were measured. The axis of toric IOL was measured with PicPickTools (NGWIN, Seoul, Korea) using photography of anterior segment under pupil dilation at postoperative 1 day and 2 months. Axis rotation of toric IOL was calculated using the difference of axis between postoperative 1 day and 2 months.

\section{Statistical analysis}

Statistical analysis was performed using a commercial program (SPSS for Windows; version 21.0.1; SPSS Inc., Chicago, IL). The Wilcoxon signed rank test was used to compare pre- and postoperative $\mathrm{BCVA}$ and refractive and keratometry astigmatism. $P$ values $<0.05$ were considered statistically significant.

\section{Results}

Thirty-one eyes of 31 patients were enrolled in the study. Table 1 summarizes the patient demographics and the preoperative data. The preoperative diagnoses comprised trichiasis, corneal ulcer, herpes keratitis, previous pterygium surgery, uveitis, traumatic corneal scar, and unknown (Table 2). Postoperative UCVA $(0.30 \pm 0.17)$ and BCVA $(0.22 \pm 0.16)$ were significantly improved compared to preoperative UCVA (1.20 \pm $0.34)$ and BCVA $(1.10 \pm 0.30)(P<0.05)$ (Fig. 2). The

Table 1 The patient demographics and the preoperative data

\begin{tabular}{ll}
\hline Parameters & \\
\hline Total patients (Eyes) & $31(31)$ \\
Male: Women (ratio) & $14: 17$ \\
Patient age (years) & $57.44 \pm 12.01$ \\
Mean auto-refractive cylinder (Diopter) & $2.40 \pm 0.65$ \\
Mean total corneal astigmatism (D) & $1.91 \pm 0.44$ \\
Mean BCVA (logMAR) & $1.10 \pm 0.30$
\end{tabular}

Data represent mean \pm standard deviation
Table 2 The causes of corneal opacity

\begin{tabular}{ll}
\hline & Number of eyes \\
\hline Trichiasis & 3 \\
Corneal ulcer & 5 \\
Herpes keratitis & 2 \\
Previous pterygium surgery & 3 \\
Uveitis & 5 \\
Traumatic corneal scar & 6 \\
Unknown & 7 \\
Total & 31 \\
\hline
\end{tabular}

UCVA 2 months postoperatively was $20 / 32$ or better in 19 eyes (61.3\%) and $20 / 25$ or better in 7 eyes (22.6\%) (Fig. 3). The postoperative residual refractive astigmatism (1.20 \pm 0.35 D) was significantly reduced compared to preoperative refractive astigmatism $(2.4 \pm 0.65 \mathrm{D})(P<0.05)$. Preoperative and postoperative total corneal astigmatism $(1.91 \pm 0.44 \& 1.52 \pm$ $0.38 \mathrm{D}$, respectively) were not significantly different (Fig. 4). The percentage of patients with residual astigmatism within $\pm 0.5 \mathrm{D}$ was $22.6 \%$ (7 eyes of 31 ), and that with residual astigmatism within $\pm 1.0 \mathrm{D}$ was $60 \%$ (18 eyes of 31 ) (Fig. 5).

$100 \%$ cases achieved UCVA and BCVA were as good as or better than that preoperatively with correction. $42.9 \%$ cases achieved better UCVA compared to preoperative BCVA 0.5 logMAR over and $77.4 \%$ cases achieved better BCVA compared to preoperative BCVA $0.5 \log$ MAR over (Fig. 6a and b). The size of corneal opacity covering pupil had significant positive correlation with postoperative UCVA and BCVA (logMAR) ( $R=0.91 P<0.05$ and $R=0.92 \quad P<0.05$, respectively) (Fig. 7). The size of corneal opacity covering pupil had significant positive correlation with and preoperative attempted correction - postoperative corrected astigmatism (D) $(R=0.94, P<0.05)$ (Fig. 8). Axis rotation of the TIOL between postoperative 1 day and 2 months after cataract surgery was $3.25 \pm 1.44$ degrees. Achieved correction of astigmatism (preoperative - postoperative refractive astigmatism) was significantly smaller than attempted correction of astigmatism $(P<0.05)$ (Fig. 9).

The vector analysis are described in Table 3 . The target astigmatism (TA) was $1.75 \pm 0.58 \mathrm{D}$, and the corrected astigmatism (CA) with toric IOLs was $1.23 \pm 0.64$ $D$. The angle of error between the axis of CA and TA was $2.19 \pm 1.32$ degrees, and the difference of vector (DV) was $0.95 \pm 0.67 \mathrm{D}$. The astigmatism correction index (CA/TA) was 0.70 , and the index of success (DV/ TA) was 0.54 .

Figure 10 shows data from a 77-year-old male patient treated for bacterial keratitis in his right eye. His inferior temporal cornea was opaque and very thin (Fig. 10b) 


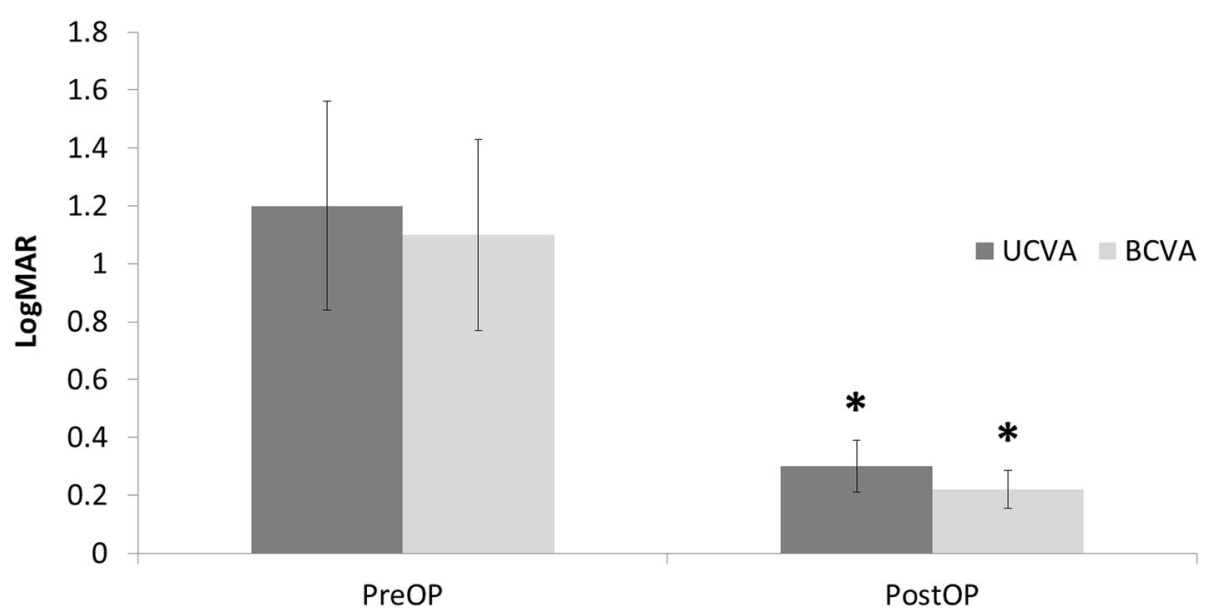

Fig. 2 Preoperative and 2 month postoperative visual acuity Values are presented as mean \pm SD. UCVA: uncorrected visual acuity, BCVA: best corrected visual acuity, Postoperative UCVA $(0.30 \pm 0.17)$ and BCVA $(0.22 \pm 0.16)$ were significantly improved compared to preoperative UCVA $(1.20 \pm 0.34)$ and BCVA $(1.10 \pm 0.30)(P<0.05)$

because of previous bacterial keratitis (Fig. 10a). His preoperative BCVA was 20/200 and refractive astigmatism was 2.5D. After a Tecnis ZCT225 was inserted, postoperative 2 month UCVA was 20/22, BCVA was 20/20, and residual refractive astigmatism was 1.0D. Figure 11 involves a 63-year-old female patient who reported central corneal opacity in her right eye from birth. Her preoperative BCVA was 20/60 and refractive astigmatism was $2.75 \mathrm{D}$. After a Tecnis ZCT300 was inserted, her postoperative 2 month UCVA was 20/24, BCVA was 20/ 22 , and residual refractive astigmatism was $1.25 \mathrm{D}$.

\section{Discussion}

About $60 \%$ of patients with normal corneas that undergo cataract surgery have more than $0.75 \mathrm{D}$ of corneal astigmatism [6]. Therefore, patients with cataract and corneal opacity have greater corneal astigmatism than the normal population [7]. Consequently, simultaneous penetrating keratoplasty and cataract surgery may be the preferred treatment option in this patient group [2, 8]. However, simultaneous penetrating keratoplasty and cataract surgery may induce more astigmatism than the preoperative condition [2, 8]. Phacoemulsification and

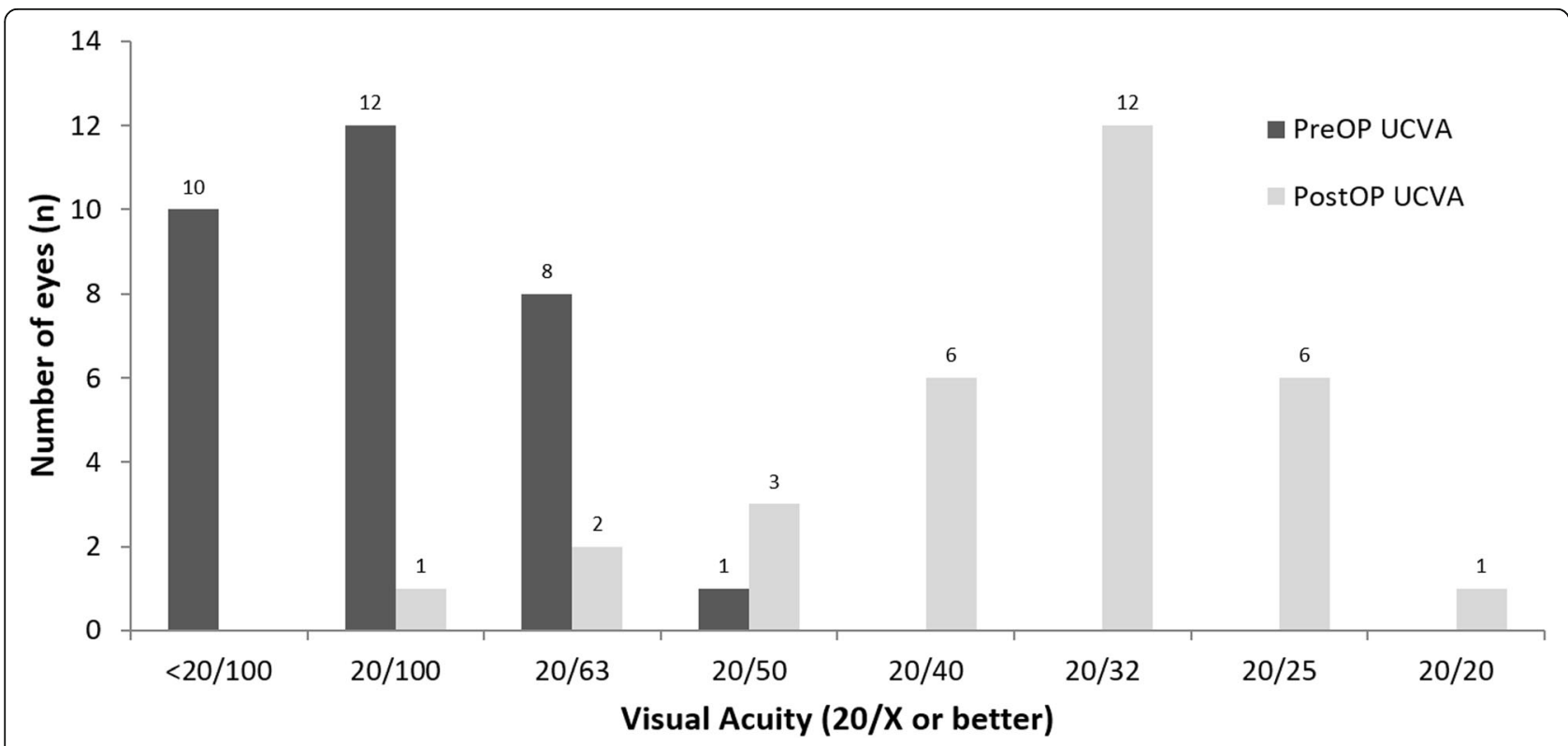

Fig. 3 Preoperative and 2 month postoperative visual acuity distribution, Values are presented as mean \pm SD. UCVA: uncorrected visual acuity, The UCVA 2 months postoperatively was 20/32 or better in 19 eyes (61.3\%) and 20/25 or better in 7 eyes 


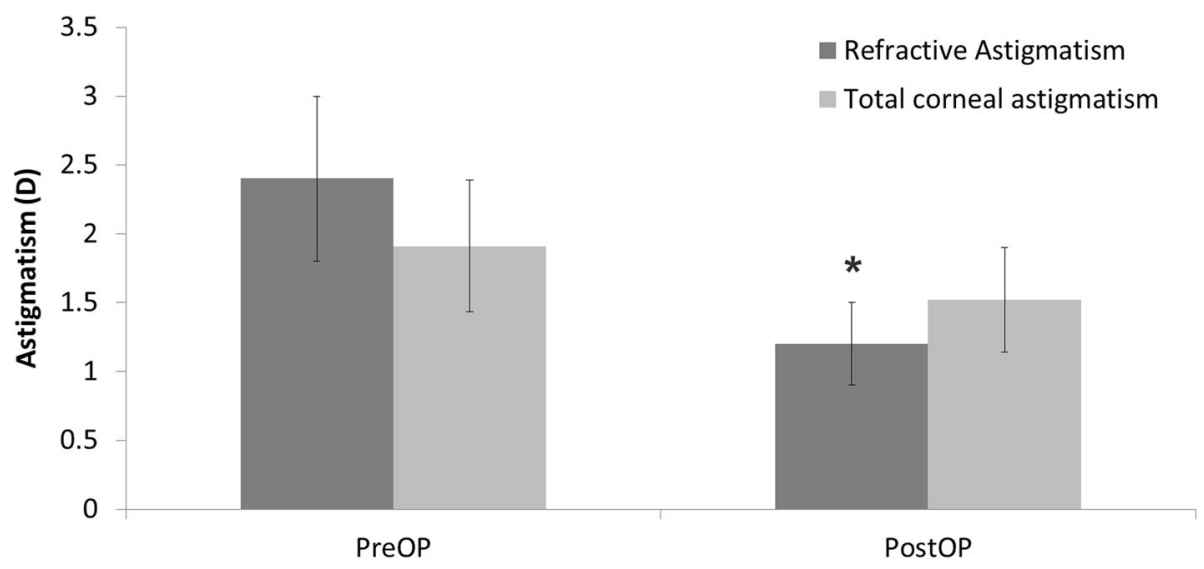

Fig. 4 Preoperative and 2 month postoperative astigmatism, Values are presented as mean $\pm S D$. D: Diopter, Postoperative residual refractive astigmatism (1.20 $\pm 0.35 \mathrm{D})$ was statistically reduced compared to preoperative refractive astigmatism $(2.4 \pm 0.65 \mathrm{D})(P<0.05)$

IOL implantation in selected cases of coexisting cataract and corneal opacity are safe and can provide suboptimal but long-term vision when penetrating keratoplasty is not an option or there is a high risk of graft failure [4]. Cataract surgery with toric IOL implantation could better improve visual acuity than simultaneous penetrating keratoplasty and cataract surgery when the central cornea is not totally opaque [3]. BCVA improvements after surgery are less likely for more severe opacity indices that involve the pupil, according to the reflectivity signal [4].

In this study, postoperative UCVA $(0.30 \pm 0.17)$ and BCVA $(0.22 \pm 0.16)$ were significantly improved compared to preoperative UCVA $(1.20 \pm 0.34)$ and BCVA $(1.10 \pm 0.30)(P<0.05)$. Ho et al. reported preoperative mean UCVA and BCVA of 20/800 and 20/630, respectively, which significantly improved to $20 / 200$ and $20 / 160(P<0.001)$ after cataract surgery with monofocal IOL implantation in patients with corneal opacity [4]. In the Ho et al.'s study, the amount of visual acuity improvement was less than that in our study, because astigmatism was not corrected in this study [4].

Müftüoğlu İK reported that mean preoperative BCVA significantly increased $(0.7 \pm 0.3$ [range: $0.3-1.3$ ] logMAR to $0.1 \pm 0.04$ [range: $0.05-0.15$ ] $\operatorname{logMAR} ; P<0.05$ ) at a mean of $8.71 \pm 64.11$ months after cataract surgery with

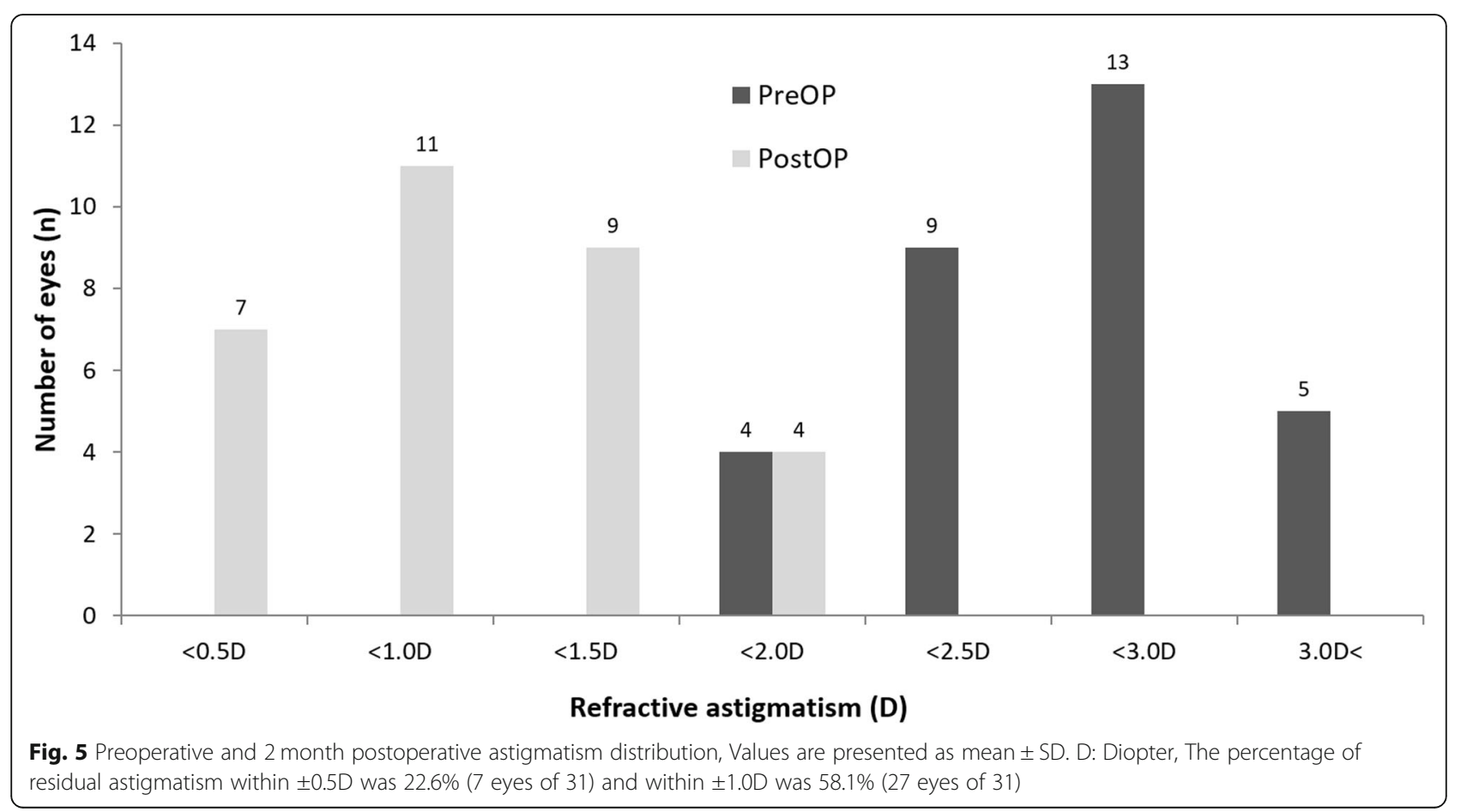



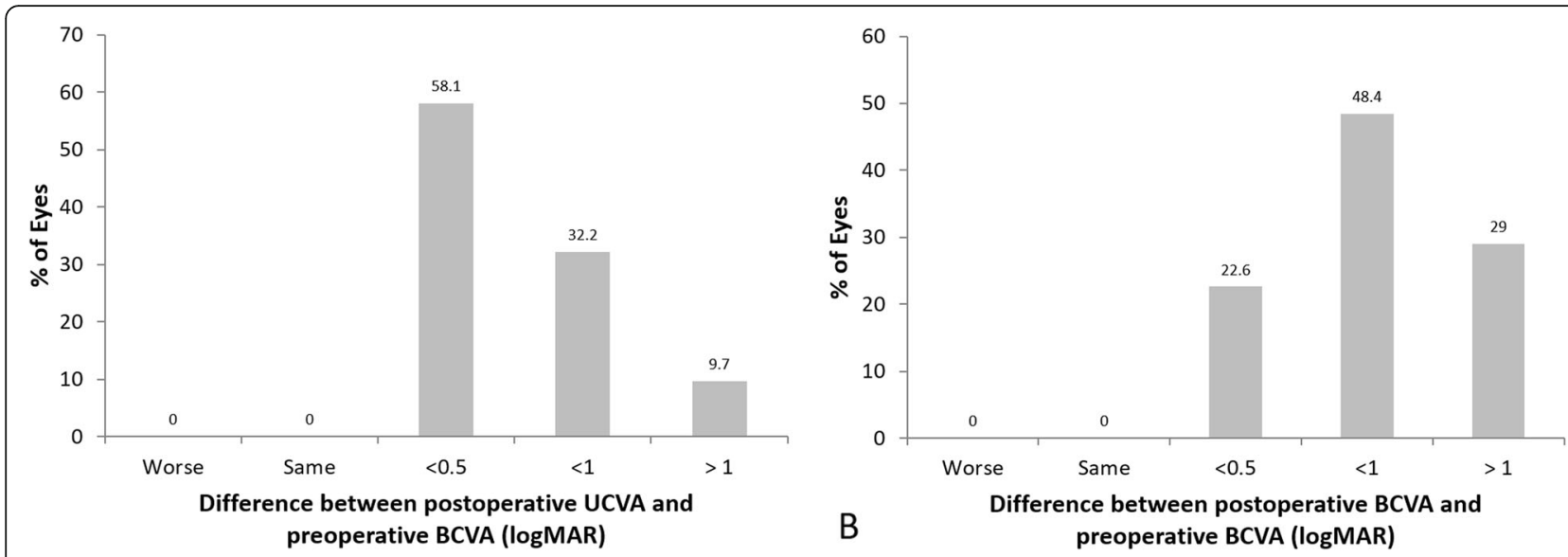

Fig. 6 Comparison of preoperative BCVA and postoperative UCVA (a) \& BCVA (b) in logMAR. Values are presented as mean $\pm S D$. UCVA: Uncorrected visual acuity, BCVA: Best corrected visual acuity, 100\% cases achieved UCVA and BCVA were as good as or better than that preoperatively with correction

toric IOL implantation in patients with cataract formation and high astigmatism after penetrating keratoplasty [9]. Development of cataract is highly possible after PK because of chronic high-dose steroid use and surgical intervention. Toric IOLs are reported to be an effective modality to correct astigmatism in patients with cataract [10-12]. Additionally, visual acuity improvement was greater in the study by Müftüoğlu İK than in our study, because the corneas in their study were relatively clear after PK compared to those in our study.

In this study, the 2 month postoperative UCVA was $20 / 32$ or better in 19 eyes $(61.3 \%$ ) and $20 / 25$ or better in 7 eyes $(22.6 \%)$. This indicates that the majority of patients who underwent toric IOL implantation will not need to wear glasses daily. The corrected distance Snellen visual acuity (with spectacles or contact lenses) 12 months postoperatively was $20 / 32$ or better in $82 \%$ of eyes in keratoconus patients with toric IOL implantation [13]. In the normal cataract patients that did not have corneal opacity, mean LogMAR UDVA and BDVA were $0.19 \pm 0.12$ and $0.14 \pm 0.10$, respectively. In addition, a postoperative UDVA of $20 / 40$ or better was achieved in $92.6 \%$ of eyes [14].

In this study, postoperative residual refractive astigmatism $(1.20 \pm 0.35 \mathrm{D})$ was significantly reduced compared to preoperative refractive astigmatism $(2.4 \pm 0.65 \mathrm{D})(P<$ $0.05)$. Müftüoğlu İK reported that the mean preoperative corneal keratometric astigmatism was $5.4 \pm 0.9 \mathrm{D}$ (range: $4.25-7.00 \mathrm{D}$ ) at the corneal plane and $6.3 \pm 1.0 \mathrm{D}$ (range: 4.9-8.1 D) at the spectacle plane, and the average manifest refractive astigmatism was $1.5 \pm 0.7 \mathrm{D}$ (range: $0.25-$ $2.25 \mathrm{D})$ at postoperative month 1 after toric IOL implantation in patients that had previously undergone penetrating keratoplasty [9]. Postoperative refractive astigmatism significantly decreased in their study, which was in agreement with the results of our study. In contrast, refractive astigmatism persisted after cataract
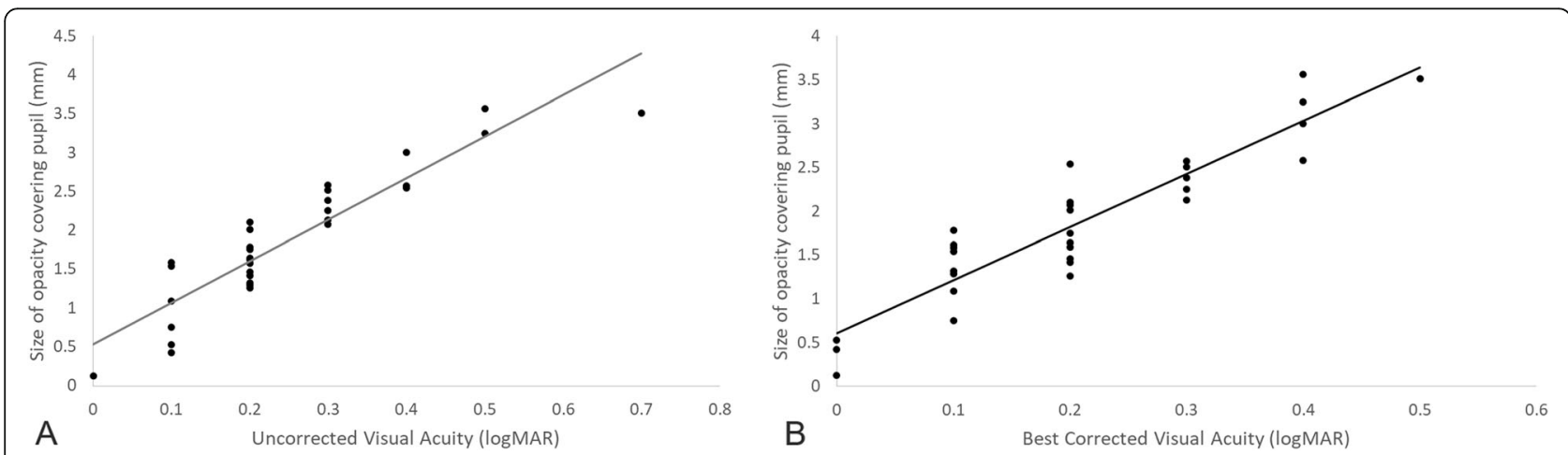

Fig. 7 Correlation of the size of corneal opacity covering pupill and postoperative UCVA (a) and BCVA (b) (logMAR). UCVA: Uncorrected visual acuity, BCVA: Best corrected visual acuity, The size of corneal opacity covering pupil had significant positive correlation with postoperative UCVA and BCVA (logMAR) $(R=0.91 P<0.05$ and $R=0.92 P<0.05$, respectively) 


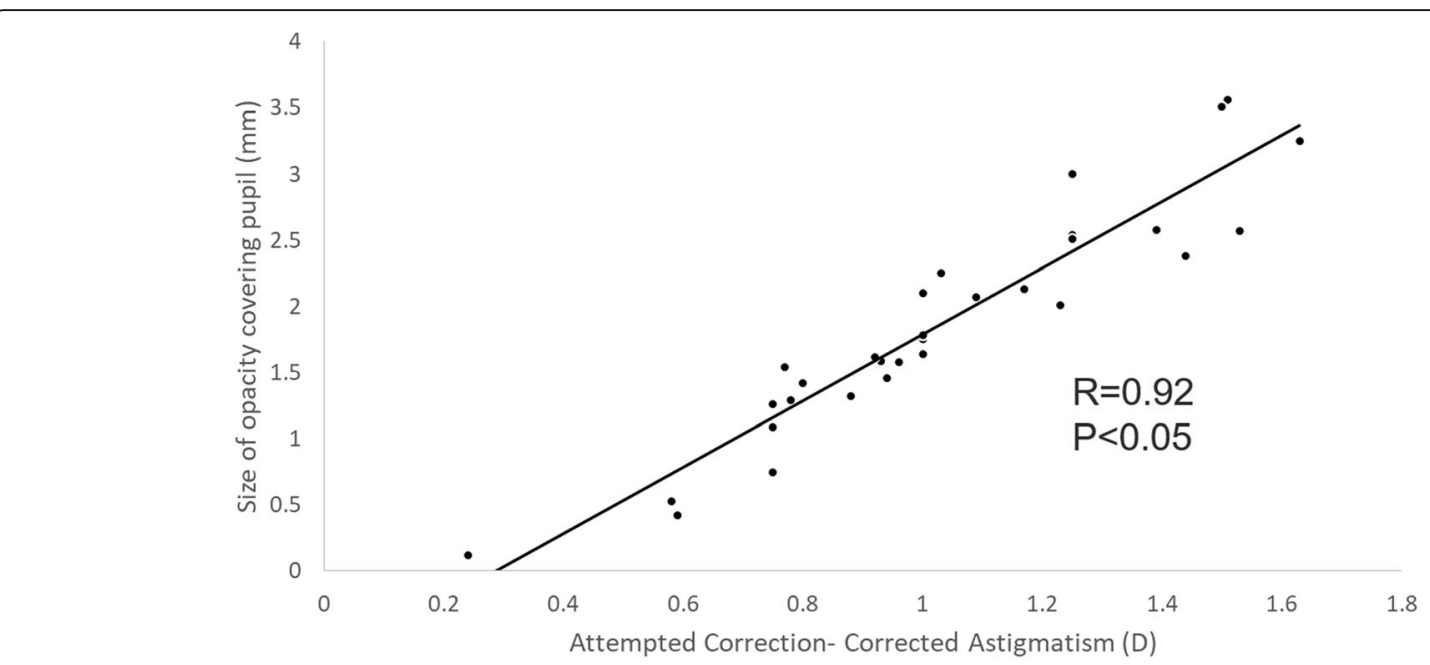

Fig. 8 Correlation of the size of corneal opacity covering pupill and preoperative attempted correction - postoperative corrected astigmatism (D). D: Diopter, The size of corneal opacity covering pupil had significant positive correlation with and preoperative attempted correction postoperative corrected astigmatism (D) $(R=0.94, P<0.05)$

surgery with monofocal IOL implantation [4]. In normal cataract patients without corneal opacity, mean refractive cylinder decreased significantly from $-3.73 \pm 1.96$ to $-1.42 \pm 0.88 \mathrm{D}(\quad<0.001)$, while keratometric cylinder did not change significantly $(\mathrm{P}=0.44)$ after toric IOL implantation [14]. The visual and refractive astigmatic outcomes inferior to normal cataract without corneal opacity, but improved even though there was corneal opacity in this study.
In another study, 92.3\% cases achieved visual acuity were as good as or better than that preoperatively with correction after monofocal IOL implantation [4]. However, in this study, all cases achieved postoperative visual acuity as good as or better than preoperative one after toric IOL implantation.

In central corneal opacity, phacoemulsification should be performed when the extent of opacity is small enough to improve visual acuity after surgery [15]. In this study,

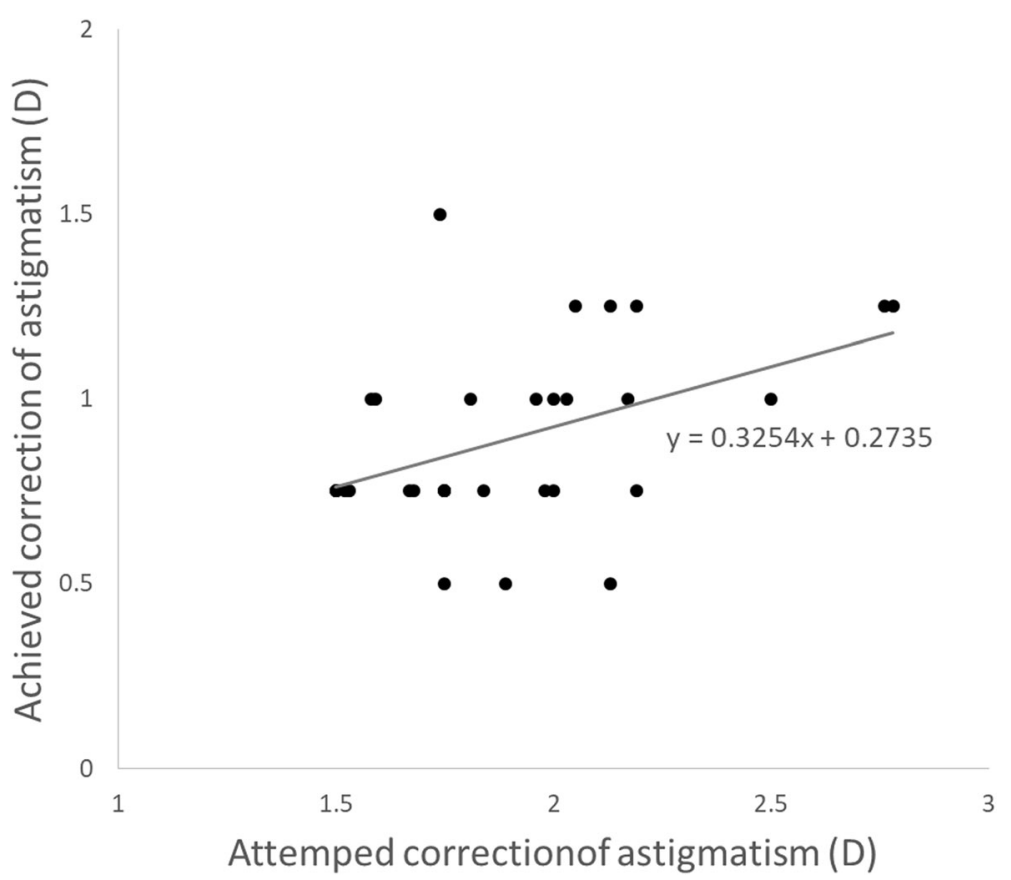

Fig. 9 Comparison of Achieved correction of astigmatism and attempted correction of astigmatism (D). Achieved correction of astigmatism (preoperative - postoperative refractive astigmatism) was significantly smaller than attempted correction of astigmatism $(P<0.05)$ 
Table 3 Vector analysis of toric IOLs

\begin{tabular}{ll}
\hline Parameter & Mean \pm SD \\
\hline Target astigmatism (TA) (D) & $1.75 \pm 0.58$ \\
Corrected astigmatism (CA) (D) & $1.23 \pm 0.64$ \\
Angle of error between the axis of CA and TA (degree) & $2.19 \pm 1.32$ \\
Difference of vector (DV) (D) & $0.95 \pm 0.67$ \\
Astigmatism correction index (CA /TA) & 0.70 \\
Index of success (DV/TA) & 0.54 \\
\hline
\end{tabular}

we included patients with peripheral corneal opacity as demonstrated in Fig. 10, and large central corneal opacity as in Fig. 11. Patient with peripheral corneal opacity had more improved postoperative UCVA and BCVA compared to patient with central corneal opacity, in these cases. Regarding visual outcome, Ho Y. et al. reported that there is no significant correlation between logMAR BCVA and corneal densitometry and OCT grading $(P>0.05)$ [4]. However, in this study, the size of corneal opacity covering pupil had significant negative correlation with postoperative UCVA and BCVA (logMAR) $(R=0.91 \quad P<0.05$ and $R=0.92 P<0.05$, respectively) (Fig. 7). The size of corneal opacity covering pupil had significant positive correlation with and preoperative attempted correction - postoperative corrected astigmatism (D) $(R=$ 0.94, $P<0.05$ ) (Fig. 8). The patients with central corneal opacity had poor visual outcome and astigmatic correction because the opacity occurred in early childhood, the central light cannot passed to the retina properly, and the patients had relatively irregular corneal astigmatism compared to patients with peripheral corneal opacity."

In this study, achieved correction of astigmatism (preoperative -postoperative refractive astigmatism) was significantly smaller than attempted correction of astigmatism $(P<0.05)$ (Fig. 9). The correction of astigmatism using toric IOL was inaccurate compared to normal patients with clear cornea, because corneal opacity might inhibit precise measurement of preoperative total corneal astigmatism.

The corneal astigmatism associated with corneal opacity should not be considered same as regular corneal astigmatism for the selection of toric IOL. Toric IOL can be undercorrected (Fig. 9) because of relatively skewed deviation of axis and uneven surface of cornea.

Therefore, we concluded that not the central corneal opacity size, but the size of corneal opacity covering pupil was the major prognostic factor for postoperative visual improvement. Patients with paracentral corneal opacity are the best candidates for cataract surgery to optimize vision [15]. But, if corneal opacity did not cover the whole central pupillary area, good vision can be achieved with cataract surgery and toric IOL implantation.

In the vector analysis, the target astigmatism (TA) was $1.75 \pm 0.58 \mathrm{D}$, and the corrected astigmatism (CA) with toric IOLs was $1.23 \pm 0.64 \mathrm{D}$. The angle of error between the axis of CA and TA was $2.19 \pm 1.32$ degrees, and the difference of vector (DV) was $0.95 \pm 0.67 \mathrm{D}$. The astigmatism correction index (CA/TA) was 0.70 , and the index of success (DV/TA) was 0.54. The astigmatism correction index was not near the ideal of 1 , and the index of success was far from the ideal of 0 (Table 3).

In other study of normal corneal patients, the astigmatism correction index was 0.95 , but the index of success was 0.44 after toric IOLs implantation [16].

We hypothesized that this inaccuracy of correction compared to normal patients occurs because of the undercorrection of total corneal astigmatism, irregular corneal surface, and corneal opacity covering central pupillary area.

Despite of inaccurate correction of astigmatism in patients with opacity covering large part of covering pupil, the visual acuity was improved (in the size of opacity covering pupil $2 \mathrm{~mm}, 0.2 \operatorname{logMAR}$ of uncorrected visual

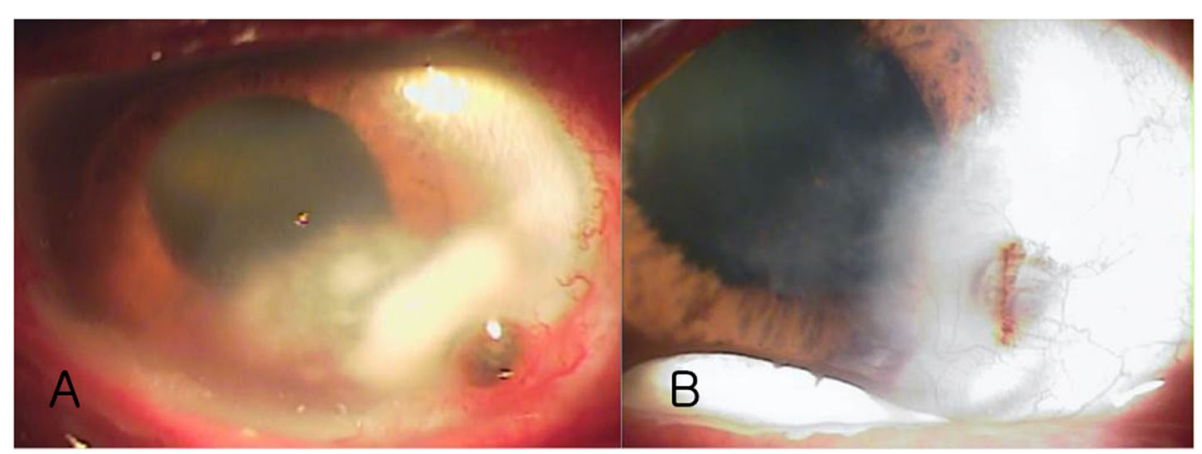

Fig. 10 Preoperative image of a patient treated for bacterial keratitis. Inferior temporal cornea is opaque and very thin (Fig. 7b) because of previous bacterial keratitis (Fig. 7a). The patient's preoperative UCVA, BCVA, and refractive astigmatism improved at 2 months postoperatively 


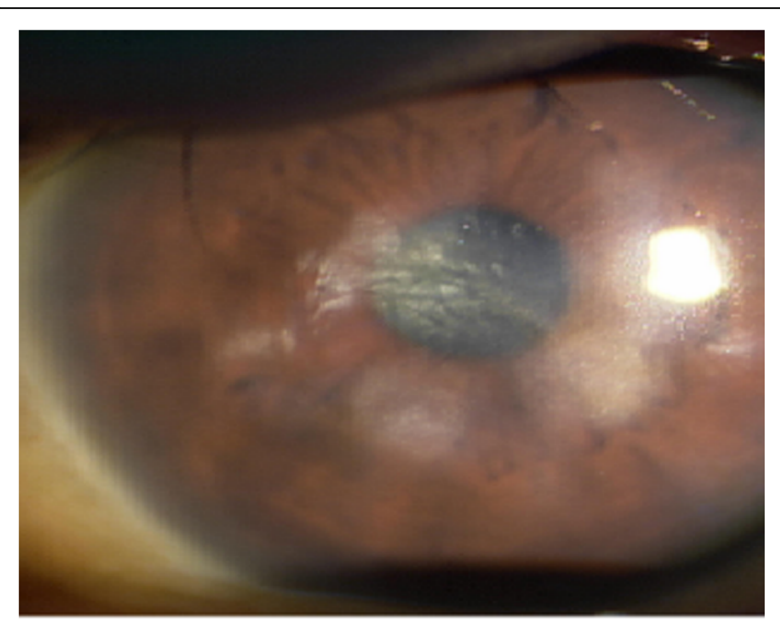

Fig. 11 Preoperative image of a patient with congenital central corneal opacity. The patient's preoperative UCVA, BCVA, and refractive astigmatism were improved at 2 months postoperatively

acuity and $0.3 \log$ MAR of best corrected visual acuity in Fig. 7).

Therefore, we think it is worthy of implantation toric IOLs in patients with corneal opacity, despite of relatively inaccurate correction compared to normal patients with clear cornea.

This was the first study to evaluate toric IOL implantation outcomes in cataract patients with corneal opacity. The postoperative visual acuity was significantly improved in spite of the previously existing corneal opacity. The postoperative residual refractive astigmatism was also significantly improved. Postoperative UCVA and BCVA were correlated with the percentage of corneal opacity covering pupillary area. Therefore, toric IOL implantation is effective for improving visual acuity in patients with corneal opacity and cataract.

The short duration of follow up ( 2 month) and lack of control over the monofocal IOL of the subjects were among the limitations of this study. A multicenter clinical trial with a larger sample size and longer follow up period is suggested to observe the long-term efficacy of the toric intraocular lens implantation in cataract patients with corneal opacity.

\section{Conclusions}

Toric intraocular lens implantation can improve visual acuity and refractive astigmatism in cataract patient with corneal opacity. The percentage of central corneal opacity covering pupillary area is the major prognostic factor for postoperative visual improvement. Therefore, toric intraocular lens implantation should be considered for cataract patients who have corneal opacity with regular astigmatism.

\section{Supplementary information}

Supplementary information accompanies this paper at https://doi.org/10. 1186/s12886-020-01352-w.

Additional file 1: Video. Implantation of Toric Intraocular Lens in Patient with Cataract and Corneal Opacity. Toric Intraocular Lens was implanted in patient with central corneal opacity.

\section{Abbreviations}

BCVA: Best corrected visual acuity; LogMAR: Logarithm of the Minimum Angle of Resolution; TIOL: Toric intraocular lens; UCVA: Uncorrected visual acuity

\section{Acknowledgements}

None.

\section{Authors' contributions}

HR was involved in analysis and interpretation of data and drafting the manuscript. HSH, HSK, and MSK made contribution to acquisition of data and drafting. ECK contributed to conception and design, analysis and interpretation of data, drafting and revising the manuscript. All authors read and approved the final manuscript.

\section{Funding}

This research was supported by the Basic Science Research Program through the National Research Foundation of Korea (NRF) funded by the Ministry of Education (2018R1D1A1A02085334). The funding offered support in the design of the study and collection, analysis, interpretation of data, and publication fee.

\section{Availability of data and materials}

The datasets used and/or analyzed during the current study available from the corresponding author on reasonable request.

\section{Ethics approval and consent to participate}

This study was approved by the institutional review board at Bucheon St. Mary's Hospital (HC16RISI0035); the informed consent was waived. All clinical investigations have been conducted according to the principles expressed in the Declaration of Helsinki.

\section{Consent for publication}

Not applicable.

\section{Competing interests}

Coauthor, Ho Sik Hwang, is an Editorial Board member of BMC Ophthalmology.

Received: 18 October 2019 Accepted: 18 February 2020

Published online: 13 March 2020

\section{References}

1. Javadi MA, Feizi S, Moein HR. Simultaneous penetrating keratoplasty and cataract surgery. J Ophthalmic Vis Res. 2013;8(1):39-46.

2. Shimmura S, Ohashi Y, Shiroma H, Shimazaki J, Tsubota K. Corneal opacity and cataract: triple procedure versus secondary approach. Cornea. 2003; 22(3):234-8.

3. Panda A, Krishna SN, Dada T. Outcome of phacoemulsification in eyes with cataract and cornea opacity partially obscuring the pupillary area. Nepal J Ophthalmol. 2012;4(2):217-23.

4. Ho YJ, Sun CC, Chen HC. Cataract surgery in patients with corneal opacities. BMC Ophthalmol. 2018;18(1):106.

5. Agresta B, Knorz MC, Donatti C, Jackson D. Visual acuity improvements after implantation of toric intraocular lenses in cataract patients with astigmatism: a systematic review. BMC Ophthalmol. 2012;12:41.

6. Hoffmann PC, Hutz WW. Analysis of biometry and prevalence data for corneal astigmatism in 23,239 eyes. J Cataract Refract Surg. 2010;36(9): 1479-85.

7. Bouzas A, Marcakis G. Correlation between corneal leukoma and induced astigmatism. Bulletins et memoires de la Societe francaise d'ophtalmologie. 1986;97:201-3. 
8. Hayashi K, Hayashi H. Simultaneous versus sequential penetrating keratoplasty and cataract surgery. Cornea. 2006;25(9):1020-5.

9. Muftuoglu IK, Akova YA, Egrilmez S, Yilmaz SG. The results of Toric intraocular Lens implantation in patients with cataract and high astigmatism after penetrating Keratoplasty. Eye Contact Lens. 2016;42(2): e8-e11.

10. Mendicute J, Irigoyen C, Aramberri J, Ondarra A, Montes-Mico R. Foldable toric intraocular lens for astigmatism correction in cataract patients. J Cataract Refract Surg. 2008;34(4):601-7.

11. Chang DF. Comparative rotational stability of single-piece open-loop acrylic and plate-haptic silicone toric intraocular lenses. J Cataract Refract Surg. 2008;34(11):1842-7.

12. Bauer NJ, de Vries NE, Webers CA, Hendrikse F, Nuijts RM. Astigmatism management in cataract surgery with the AcrySof toric intraocular lens. J Cataract Refract Surg. 2008:34(9):1483-8.

13. Mol IE, Van Dooren BT. Toric intraocular lenses for correction of astigmatism in keratoconus and after corneal surgery. Clin Ophthalmol. 2016;10:1153-9.

14. Lubinski W, Kazmierczak B, Gronkowska-Serafin J, Podboraczynska-Jodko K. Clinical outcomes after uncomplicated cataract surgery with implantation of the Tecnis Toric intraocular Lens. J Ophthalmol. 2016;2016:3257217.

15. Sharma N, Singhal D, Maharana PK, Dhiman R, Shekhar H, Titiyal JS, Agarwal T. Phacoemulsification with coexisting corneal opacities. J Cataract Refract Surg. 2019;45(1):94-100.

16. Kawahara A, Takayanagi Y. Vector analysis investigation of toric intraocular lens with no deviation from the intended axis. Clin Ophthalmol. 2016;10: 2199-203.

\section{Publisher's Note}

Springer Nature remains neutral with regard to jurisdictional claims in published maps and institutional affiliations.

Ready to submit your research? Choose BMC and benefit from:

- fast, convenient online submission

- thorough peer review by experienced researchers in your field

- rapid publication on acceptance

- support for research data, including large and complex data types

- gold Open Access which fosters wider collaboration and increased citations

- maximum visibility for your research: over $100 \mathrm{M}$ website views per year

At $\mathrm{BMC}$, research is always in progress.

Learn more biomedcentral.com/submissions 